\title{
The importance of researching general components of diagnostic thinking in modern psychology
}

Keywords: diagnostic thinking, causal approaches to diagnostics, non-specific elements of diagnostic search, cognitive model of solving process of diagnostics searching tasks

\section{Mini review}

Diagnostic thinking is a kind of practical thinking, which provided the searching process of actual cause (causes), which determined specific condition of diagnostics object. ${ }^{1,2}$ Diagnostic thinking is an important process in different kinds of professional activity. In the modern world of dynamic scientific and informational revolution, millions of qualified professionals in diagnostics are occupied in the field of verification of the various states of various objects. Economical, social and political systems and institutions, law enforcement, education, health organizations, the states, families, persons all need correct and timely diagnoses. The results of diagnostic knowledge are used by health professionals, managers, and politics, consulting firms, law enforcement and the military, educators, psychologists. Diagnostic thinking is a human activity. Diagnostic thinking includes the diagnostic cycle as a whole, and its errors lead to distortion product of diagnostics-the diagnostic conclusion. The unawareness of psychological laws of diagnostic knowledge leads to mistakes, erroneous decision-making, wrong diagnosis, and decreased efficiency of the relevant field of practice. ${ }^{3}$ Consequently, we should mention, that professional effectiveness in this case depends not merely on the mastery in the relevant field of knowledge, but also on awareness of psychology of diagnostic thinking. In many types of diagnostics there are some researches, which devoted to different aspects of thinking within some profession. For illustration we should mention studies in technical diagnostics, ${ }^{4-8}$ medical diagnostics ${ }^{9-15}$ and psychological diagnostics. ${ }^{16-21}$ In these works had been studied such aspects of process of solving diagnostic tasks as thinking as installed beforehand system of conceptions (its provide the semiotic component of diagnostics), the specific features of diagnostics recognizing, different types of diagnostic errors and stages of diagnostic process (this stages provide the gnostic component of diagnostics). Also in this materials authors considering some approaches to leaning of diagnostic skills.

We'd like to point out, that special considering of diagnostic thinking realized in frames of causal approach. ${ }^{1,22}$ Casual approach, worked out by A.F. Anyfriev, reveal itself first in psycho diagnostic field of study. It became the third force in psycho diagnostic, because in the past we saw only two forces-psychometric (which understand subject of psycho diagnostic as applying of diagnostic tests and so on) and clinical approaches (which aimed on considering only ideographical aspects of its subject). Causal approach research different aspects of diagnostic thinking, for example strategies and typical errors of diagnostic thinking, components of diagnostics (semiotic, gnostic, technical and deontological component for kinds of diagnostics, which involved humans as its subject) and so on. ${ }^{23-25}$ Also this approach studied the connection between different personal qualities and efficiency of diagnostic thinking. ${ }^{26,27}$ On mentioned base causal approach modeling computer diagnostic tasks (in current time only psycho diagnostic tasks). ${ }^{28}$ These tasks are based on three principles: excess of data, actuality of diagnostic cases and causal relations

\author{
Volume 9 Issue 3 - 2018
}

\section{Chmel Victor Ivanovich, Anufriev Alexander Fedorovich}

Department of Pedagogical and Psychology, Moscow State Pedagogical University, Russia

Correspondence: Chmel Victor Ivanovich, Department of Pedagogical and Psychology, Moscow State Pedagogical University, Moscow, Russia, Email rent32@rambler.ru

Received: December 27, 2016 | Published: May 092018

between phenomenal and cause levels of a person. Consequently these tasks give the opportunity to specialists, who solve these tasks, the freedom in their activity (it may be teachers, psychologists, students of psychological faculties and so on.). And when they have finished, we may investigate through this computer models their diagnostic thinking (time of solving, number of hypothesis and so on). It creates the conditions for the competent assessment and teaching in psycho diagnostic sphere. But very important to mention, that the general idea of the casual approach-diagnostic thinking has basic aspects, which irrespective to different specific kinds of diagnostic, e.g. this approach consists on existence of general aspect of all kinds of professional diagnostics. Causal approach determined diagnostics as science of solving diagnostic tasks-construction, assessment and search kind of tasks. ${ }^{1,22}$ Construction tasks connected with process of creating of diagnostic measurement instruments. This task indirectly connected with diagnostic activity, because they involved science and research skills (not diagnostic). Assessment tasks aimed on measuring different diagnostic indicators (presence or lack and also degree of its manifestation). Search diagnostic tasks direct on searching process of actual cause (causes), which determined specific condition of diagnostics object. Exactly these kind tasks (searching tasks) involve difficult process of diagnostic thinking in their solving. The latest researches in causal approach reveal general basis of diagnostic thinking. In first article,$^{29}$ which devoted to non-specific elements of diagnostic search, described their researching, this manifested the existence of these non-specific elements in different particular kinds of diagnostic. It has been shown, that non-specific elements of diagnostic search forming when the students of near future professions, which assumed diagnostic component (psychologists and defectologists) are solving simple diagnostic tasks-puzzles. It provides by means of trainer Diagnostic search. Approbation of diagnostic search displayed, that diagnostic work with it involve basic general diagnostic skills (typical strategies of diagnostic thinking, conception about two-level object of diagnostics etc.). In our research two groups of students have solving diagnostic tasks-puzzles, which imply finding the cause of certain dispersion of dots. We must note that formerly, all mentioned students don't have experience to solving specially organized diagnostic tasks in any particular kind 
of diagnostics. After analysis and comparison of information receive from solving tasks by test subject on Diagnostic search, which include using strategies of thinking and typical diagnostic errors, graphical data about time of solving tasks, number of hypothesis, emerging barriers, etc., interpreted results of this experiment have demonstrated similar forming and actualization of diagnostic skills among the group of examinees. We find out next non-specific elements of diagnostic search:

\section{Orientation on content of diagnostic task}

2. Tendency to optimal diagnostic stage

3. Operation of diagnostic images

4. Set to actual correctness of diagnoses

\section{Set to efficiency of diagnoses}

We also demonstrate that without non-specific elements, diagnostic search turns to formal enumeration of different causes of deviation.

In second article, ${ }^{30}$ which devoted to cognitive model of solving process of diagnostics searching tasks, we displayed that mentioned cognitive model include five non-specific elements of diagnostic search, which are have status of general psychology components, which have similar developing and manifestation in different kinds of diagnostics, and serve as strategic guidelines in diagnostic activity, affecting positively on this activity. Empirical verification of considering cognitive model is conducted by two methods:

1. When two groups of different specialist are solving the same diagnostic tasks (simple diagnostic tasks-puzzles).

2. When two groups of the same specialist are solving diagnostic (psychological) tasks, which has different semiotic constructs.

Beside aforementioned facts, we also find out specific condition of engagement, which display itself, when the cognitive model of solving process of diagnostics tasks gradually forming at probationers, and which near to flow, described by M. Csikszentmihalyi. ${ }^{31}$ In third article, ${ }^{32}$ which devoted to diagnostic skill, we displayed that diagnostic skill, which display itself when the mentioned above cognitive model had been forming, may transfer to another kind of diagnostic activity, e.g. forming before in context of solving simple diagnostic taskspuzzles diagnostic skill may have positive influence on efficiency of solving psycho diagnostic tasks. All these facts argued that we must organized furthest study of the cognitive model of solving process of search diagnostics tasks and non-specific elements of diagnostic search, which compose mentioned cognitive model. The findings of these researches can improve the activity of professional specialists and student's preparation, whose future profession involved diagnostic thinking. The following goal of the complex psychological research is developing technology of shaping an effective diagnostic thinking of a professional with the use of adequate instrumental means. Presently, such a technology does not exist as well as there are no serious studies of diagnostic thinking in general. The modern science de facto lacks understanding of diagnostics as a complex psychological process. The understanding of the cognitive model of solving process of diagnostics tasks by professionals both in humanitarian and technical field could lead to better effectiveness of labor of large number of professionals, avoid numerous mistakes, inflicting harm to human life and health.

\section{Acknowledgements}

None.

\section{Conflict of interest}

The authors declare that there is no conflict of interest.

\section{References}

1. Anufriev AF. Types of diagnostic tasks for a psychologist. Initsiativy XXI veka. 2014;1:42-44.

2. Karpov AV, Kornilov UK. Subject and object of practical thinking. Yaroslavl: Remder; 2004

3. Rishcova AN. The typical errors in process of solving psycho diagnostic tasks. Psychology Cand Diss. 2012.

4. Khasanov RK. Bases of technical operation of automobiles. Orenburg: GOU OGU; 2003.

5. Kobzov DYu, Zhmurov VV, Kobzova IO, et al. Stages of technica diagnosing. Sistemy Metody Tekhnologi - Systems. Methods Technologies. 2014;4(24):43-48.

6. Mechanical engineering. In: Gokcek M, editor. BKCI: InTech; 2012

7. Panov VA. Diagnostics of engine and elimination of revealed defects on places where AT is based and in recovery centers. Engine. 2011;3(75):24-27.

8. Sverchcova. Psychological analysis of the process of making a technical diagnosis. Psychology Cand Diss. 1976.

9. Friedman HH. Problem-oriented medical diagnosis. $2^{\text {nd }}$ ed. Boston: Brown and Company (Inc.); 1979:464.

10. Kornfeld IN. The algorithm of decision making in process of making diagnosis on many symptoms. Vratch-aspirant. 2013;1(1):155-161.

11. Lasted L. Introduction to the decision-making problem in medicine. Moscow: Mir; 1971

12. Osipov IV, Kopnin PV. The main issues of diagnosis theory. Tomsk: Tomsk State University; 1962.

13. Romanthsov VG. Make a diagnosis - the main task of education in medical universities. Practical and clinical medicine. 3: 150-153.

14. Sanders L. Every Patient Tells a Story: Medical Mysteries and the Art of Diagnosis. Boston: Broadway Books (Inc.); 2009.

15. Stuyt PMJ, de Vries Robbé PF, van der Meer JW. Why don't medical textbooks teach? The lack of logic in the differential diagnosis. The Journal of Medicine. 2003;61(11):383-387.

16. Ferguson J. Psychological assessment. New York: Breadth Essay for Sandy McPherson; 2002.

17. Groth-marnat G. Handbook of psychological assessment. $4^{\text {th }}$ ed. Canada: Wiley; 2003

18. Laak Jan JF. Psychodiagnostics: content and method. Moscow: MODEC; 1996.

19. Meyer GJ, Finn SE, Eyde LD. Psychological testing and psychological assessment. American Psychologist. 2001;2(56):128-165.

20. Vigitskii LS. Diagnostic of progress and pedagogical clinic of difficult childhood. 1983;5.

21. Voitco VI, Gilbush UZ. About some conceptions of psycho diagnostic. Voprosy psihologii. 1976;4:16-30. 
22. Anufriev AF. Psychodiagnostic: Fundamentals of solutions of diagnostic tasks. Moscow; 2012.

23. Kostromina SN. Investigation of psychodiagnostic task solutions by a practical psychologist. Psychology Cand Diss. 1997.

24. Kostromina SN. Structural-functional organization of diagnostic activity of education experts. Psychology Doct Diss Saint-Petersburg. 2008.

25. Vakhrushev SV. Psychodiagnostics of difficulties in training primary school teachers. Psychology Cand Diss. 1996.

26. Udina EV. Correlation between person qualities of practical psychologist and efficiency of diagnostic activity. Psychology Cand Diss. 2001.

27. Puchcova EB. The specific characteristic of solving psycho diagnostic tasks in correlate with different levels of communication. Psychology Cand Diss. 1998.
28. Anufriev AF, Chmel VI, Chabunin SG. Psychologist-diagnostic. Computer program Moscow: MGGU; 2015.

29. Anufriev AF, Chmel VI. The conception of forming the general elements of the diagnostic search. Siberian journal of psychology. 2016;59:62-82.

30. Anufriev AF, Chmel VI. Cognitive model of solving process of diagnostics searching tasks. Cognitive psychology in context of the problems of modern education. Monograph Moscow: MSPU; 2017:92-107.

31. Csikszentmihalyi M. Flow: The Psychology of Optimal Experience. Moscow: Alpina nonfiction; 2013.

32. Chmel VI. Diagnostic skill and its transfer to new conditions. Pedagogica I Psihologia obrazovania. 2016;4:101-112. 